\title{
Analysis of Chinese Chemical Language and Terminology
}

\author{
Hao Chang
}

\begin{abstract}
The aim of this paper aims is to analyze the Chinese characters used to express the terms and nomenclature - chemical elements, organic and inorganic compounds - often found in the science of chemistry, with a view to better understanding the Chinese cultural mindset underlying this science. Interestingly, most Chinese chemical terms have their origins in a Western worldview of chemistry; yet the former is absolutely different from the latter. Firstly, most Chinese chemical nomenclature are comprised of a single syllable radical character that has no significance. Secondly, the radical of the character that indicates the physical state of the elements and compounds are shown in Western terms. And thirdly, most of the descriptive terms are distinct from Western terminology; some have even been completely misinterpreted.
\end{abstract}

Index Terms-Chemical terms, nomenclature, John Fryer, Xu Shou.

\section{INTRODUCTION}

Language forms are often seen as having multicomponents, reflecting the observation, philosophy, and culture of human beings. Within this context, language is sometimes viewed as a significant phenomenon seeking to understand the meaning of matters which are invisible; or else is defined according to theories which argue that language is the transformation and combination of ideas, facts and words [1]. As regards the field of science: Some assert that "the progress of the sciences depends entirely on the progress of their languages"; whereas others claim that it is actually science that changes the use of language [2].

One of the best examples of the latter view is Lavoisier's chemical nomenclature reforms at the end of the 18th century. Based on his 'new acids' theory, the French chemist Lavoisier renamed dephlogisticated air - that is, phlogisticated air that was named after phlogiston theory - as oxygen; and azote as nitrogen. His nomenclature reforms, moreover, enabled chemists to know what elements are composed of what compounds, and which compounds are acid, or base, or salt. Such new terminology helped promote understanding and thinking in chemical combination and decomposition [3], [4].

However, when such scientific language was introduced into China in the middle of the 19th century, Chinese chemical translations rarely expressed the meaning or spirit of the Western counterpart; indeed, some terms even completely misunderstood the chemical spirit. As a result, Chinese chemical nomenclature provide another, and somewhat different, perspective on chemical image and thinking logic,

Manuscript received August 9, 2015; revised December 14, 2015. This work was supported by the Ministry of Science and Technology of ROC (Taiwan) under Grant MOST 103-2511-S-214 -004.

Hao Chang is with the Center for General Education, I-Shou University, Taiwan (e-mail: changhao@ isu.edu.tw). which can be seen in how the Chinese language was used to translate Western chemical terms. Hence, in this paper, we attempt to deconstruct and analyze Chinese chemical terminology with a view to better understanding the Chinese mindset as regards the science of chemistry [5].

\section{HISTORICAL BACKGROUND}

After the first Opium War (1839-41), modern Western chemistry was gradually introduced into China by so-called medical missionaries, who used it as means of spreading the Christian gospel message. Following this, the Self-Strengthening Movement (c 1861-1895) accelerated the Qing Dynasty's introduction of Western science and technology, particularly as it applied to the military industry. Chemistry, especially analytical chemistry, became a favorite Western science introduced into China, who used it as a means of analyzing the iron ore and coal deposits found in China with a view to reducing the country's expensive import costs [6].

However, along with the flood of Western science and technology into China, came the problem of translating new scientific terms and nomenclature; one of the most difficult tasks being to devise a set of standard principles through which these terms could be rendered in Chinese.

In 1871 John Fryer and Shou Xu, two of the most significant names in the development of modern chemistry in $19^{\text {th }}$ century China, published their classic Huaxue Jianyuan (Elements of Chemistry), using a single radical phonetic character. This principle, still in use today, became accepted practice for the naming of chemical elements into Chinese. However, although the 'single radical phonetic' character principle was accepted by all Chinese scholars and Western translators of the time, such characters, often with just a Western phonetic, were not easy to remember and understand. Hence, other missionaries and Chinese scholars began to translate according to the meaning of the Western terms, or their chemical properties [7].

This confused situation was to continue until 1932, when The National Institute for Compilation and Translation was founded and began to standardize the principles for translation of chemical terminology. Finally, in 1933, they published their Huaxue Mingming Yuanze (Principles of Chemical Nomenclature) which has become the basis for the translation of chemical nomenclature into the Chinese language [8].

\section{RADICAL SYLLABLE CHARACTER: NAMING ELEMENTS XING-SHENG (RADICAL-PHONETIC)}

Such characters are composed of two parts: The first part is the xing, the radical, to identify the physical, chemical, or 
material properties, and so on. For example, when the substance is liquid, its character has a water radical; when it is metal, or is made of metal, its character has a metal radical. Following the xing radical is the sheng phonetic, used to identify the sound of the character - for example, $h u$ (lake) and he (river).

The term 'radical syllable' is used to express the radical/phonetic combination in order to emphasize that such characters have their origin in the syllable of the Western term, and to stress its particularity and difference from the traditional radical phonetic characters [9], [10].

Before radical syllable characters were introduced most Chinese chemical terms were derived through imitation of the sounds of the English terms. This method not only required too many Chinese characters, but also produced imitated syllables which did not indicate to the Chinese mind any properties of the substance they represented. As a result, many translators preferred translating the 'meaning' of the Western terms, or else resorted to Chinese traditional characters. This seemed reasonable, given that most Chinese did not even know the 26 letters of the English alphabet, and would not use the so-called "barbarian" language. Consequently, the Fryer-Xu method of deriving characters for chemical elements was not so popular in the $19^{\text {th }}$ century [11].

All this raises the question: If such non-meaning characters were not easy for the Chinese to accept or use, why did Fryer and $\mathrm{Xu}$ use this translation method. Simply put, the answer is because such a principle was the easiest way to create a new character. Fryer and $\mathrm{Xu}$ argued that it was too difficult to find a descriptive character to present the meaning of the English term when they translated the elements into Chinese. Hence, they decided to render the term into Chinese through imitating the sound of the English - thus they chose a character that would imitate the sound of the first, second, or even third syllable, then added a radical to show the category of that substance. For example, calcium and magnesium were transliterated as gai er xi en and mei he nixi en, with the metal radical being added to the imitation character of first syllable to become gai and mei. There were just three radicals used in Huaxue Jianyuan: metal, water, and stone. The gas radical was first used in Chemical Terms and Nomenclature (1901) [12].

After 1908, Radical-Syllable characters become more popular, largely because they had been edited by the Qing government's Ministry of Education in their Huaxue Yuhui (Chemical Terms) publication. Hence, some of the Chinese chemical terms that were originally translated from the meaning of the Western term, were gradually transformed to become syllable imitation characters in order to conform to the Fryer-Xu principle. For example, argon and helium, were translated as xin and $x i$ according the meaning of 'lazy' and 'sun' of the Western term, respectively, but then they translated $y a$ and hai according to their first syllable [13].

\section{ChINESE INORGANIC TERMS}

In the $19^{\text {th }}$ century Chinese terms for inorganic binary compounds were basically translated after their chemical formula - for example, sodium chloride was named na lyu, which means sodium chlorine (like $\mathrm{NaCl}$ ) and aluminum oxide, two aluminum three oxygen, as in $\mathrm{Al}_{2} \mathrm{O}_{3}$. In the $20^{\text {th }}$ century, however, Chinese inorganic terms began to be influenced by Japanese inorganic terminology. Hence, in the Chinese terms for binary compounds, a hua (lit. change) was inserted in the middle of two element characters, and the order of elements was reversed. Thus sodium chloride was named as lуи hиа na - literally, chlorine changes sodium; and aluminum oxide was translated to mean three oxygen change two aluminum. Nevertheless, the insertion of the hua character in inorganic terms seemed to misunderstand the Western terminology [14].

\section{CHINESE ORGANIC TERMS}

In the $19^{\text {th }}$ century, most Chinese organic terms were transliterated, which often meant having at least five characters, many of which were often difficult for the Chinese to pronounce and remember. For example, ethylate acetone was transliterated as yi tuo li a xi duo ni, and methylated acetone as mi yi tuo li a xi duo ni [15].

Transliteration, as a basic principle for the translation of organic chemical terms used in Western chemistry, was to continue until the publication of Yu Heqin's Zhongguo Youji Mingming Cao (The Draft of Chinese Terms of Organic Chemistry). In his draft, Yu began to translate Western organic terms based on their meaning, chemical properties, or the structure of their compounds. He mostly stayed away from coining new characters in his organic terms. Moreover, although Yu's organic terms are no longer in use, his translation reforms ushered in the principle of translating organic terms based on the significance of their properties [16]. This practice was to be continued by The Committee on Scientific Terminology, the most significant organization of chemical nomenclature from 1915 to 1927.

The Chinese translations for alkanes, alkenes, alkynes, alcohols, aldehydes, ketones and ethers, still in use today, were decided by Committee on Scientific Terminology. For example, the Chinese characters for alkanes, alkenes, alkynes were coined using the 'fire' radical, because of the combustible properties of these elements. However, the characters quan, tong, and $m i$ - for aldehydes, ketones and ethers, respectively - were coined using the 'wine' radical from traditional names. Yet, the meaning of these three Chinese terms is totally distinct from the Western terms. The original meaning of quan is 'the taste of wine is changed'; tong means, literally, 'the wine is sour'; whereas $m i$ has the meaning of 'the dog is drunk'. Nonetheless, other organic terms translated by the Committee on Scientific Terminology had their origin in the Western meaning, or else were based on their chemical properties or the shape of their chemical structures [17]. But most of them were revised to radical-syllable character $\mathrm{s}$ by the Committee on Chemical Terms of National Institute for Compilation and Translation.

After the chemistry meeting of the Ministry of Education, held in 1932, scholars, experts, and officials were invited to discuss the course outline of chemistry textbooks, to defend chemistry, and to speak on the unification of chemical terms. In this historical meeting, some of organic terms were 
renamed in accordance with the principle of naming elements, namely, using a single radical-syllable character [18].

The most classic example for describing such nomenclature change is the Chinese terms for benzene [19]. After the reforms of Yu Heqin, most of the terms connected with benzene have involved the shape of its ring. However, in Principles of Chemical Nomenclature it was renamed as ben, a single syllable character with a 'grass' radical. In other words, except for the terms associated with alkanes, alkenes, alkynes, alcohols, aldehydes, ketones, ethers, and carboxylic acids, the other terms such as phenols, quinones, aromatic hydrocarbon, amines, imines, hydrazines, oximes, carbylamines, phosphines, arsines, sulfones and sulfoxides were all radical-syllable characters.

\section{DISCUSSION}

After 1933, a single radical-syllable character not only become the translation principle for new elements, but also for most of new organic compounds. This principle, however, was even more difficult for the Chinese to accept than the significant terms used in the $19^{\text {th }}$ century. Why then did this principle become the translation standard of the $20^{\text {th }}$ century? One of the most important reasons may lie in the fact that Fryer and $\mathrm{Xu}$, who translated many more books of chemistry than other translators - including texts on general chemistry, organic and inorganic chemistry, and qualitative and quantitative analysis - used this principle as the basis for their own translations. That means that not only did Fryer-Xu chemical terms convey more knowledge of chemistry than other translators, but also fulfilled Fryer's prediction that when a term is used often enough, one day it will be accepted. Consequently, most Chinese translations of chemical elements and organic compounds use a single radical-syllable character that differs from the significance of the Western term.

In terms of chemical elements translated with new Chinese terms, there are only six, namely: bromine, chlorine, hydrogen, nitrogen, oxygen and platinum.

On the other hand, there are eleven (11) chemical elements derived from traditional names, as follows: boron, carbon, copper, gold, iron, lead, mercury, phosphorus, silver, sulphur, and tin.

Using the 'gas' radical, there are eleven (11) elements, namely: chlorine, fluorine, hydrogen, nitrogen, oxygen, and the six noble elements, namely, helium, neon, argon, krypton, xenon, and the radioactive radon. On the other hand, translations using the 'stone' radical, include: arsenic, carbon, iodine, phosphorus, selenium, silicon, and sulphur.

Bromine and mercury are the two elements translated with the 'water' radical. Hereas, almost all characters of the metal elements use the 'metal' radical, with the exception of mercury. Bromine, chlorine, and platinum are the only three terms that are close to the meaning of the Western term [20].

Using traditional names, there are alcohols, aldehydes, ketones, ethers, carboxylic acids, and carbohydrates.

Like the chemical elements, there are a few significant names in Chinese organic terms, namely: alkanes, alkenes, alkynes, nitriles and urea. Moreover, again like the chemical elements, most Chinese organic terms are expressed using a radical-syllable combination. But the radical used in organic terms is different from that of the chemical elements. For example, the 'fire' radical is used in the characters for alkanes, alkenes and alkynes; whereas, alcohols, aldehydes, ketones, carboxylic acids, ethers, esters acid, anhydrides, phenols, quinones and carbohydrates use the 'wine' radical.

Along similar lines, the 'meat' radical is given to amines, imines, hydrazines, oximes, nitriles, carbylamines, urea, phosphines and arsines; whereas the aromatic hydrocarbons for example, benzene, naphthalene, indene, camphene, and pinnae - have the 'grass' radical.

Finally, characters for the heterocyclic compounds are coined with a 'mouth' radical, according to the structure of their compounds - for example, furane, thiophene, phrrole, oxazole, thiazole and phrazole; with the 'stone' radical being used for sulfones and sulfoxides [21].

\section{CONCLUSION}

The Chinese have coined more terms in the field of chemistry than any other area of scientific endeavor. This is largely because there were many chemical substances introduced into China that were not known to have existed before. Moreover, although Chinese chemical terms have been derived from Western nomenclature, they are distinctly different from but the Western derivative. Most of the Chinese chemical terms have no significance, unlike those in the West; and even where a few of the Chinese terms do have implications, these are contrary to the Western mindset. In other words, while the terms used are chemical terms, there is either little mention of any chemical ingredient, or the flavor of the Chinese language is stronger than that of the chemistry. Thus, while the Chinese chemical terms do absorb some of the syllable of the Western terms yet, through the media of Chinese language, they certainly bring out the Chinese logic and philosophy that is distinct from the Western view.

In short, the situation of Chinese chemical terms in the $19^{\text {th }}$ century was completely different to that in the $20^{\text {th }}$ century. Although the descriptive names of elements may have been easier to accept in the $19^{\text {th }}$ century, it was the radical-syllable character that finally become the nomenclature of standard. This standard was also applied to both organic and inorganic compounds until they finally all became radical-syllable character. Hence, the radical-syllable character, once considered as weird and exotic in the $19^{\text {th }}$ century, has now become so reasonable and logical in the minds of $20^{\text {th }}$ century students. What a difference education makes!

\section{REFERENCES}

[1] A. L. Lavoisier, Elements of Chemistry, Edinburgh: Creech, 1790.

[2] B. B. Chastain, "Books of the chemical revolution, part III: Traité elémentaire de chimie," Bulletin for the History of Chemistry, vol. 93, pp. 8-11, 1989.

[3] M. P. Crosland, Historical Studies in the Language of Chemistry, Cambridge: Harvard University Press, 2004, pp. 177-192.

[4] B. B. Chastain, "Books of the chemical revolution, part I: Méthode de nomenclature chimique," Bulletin for the History of Chemistry, vol. 91, pp. 7-11, 1989.

[5] D. Wright, "The great desideratum Chinese chemical nomenclature and the transmission of western chemical concepts," Chinese Science, vol. 14, pp. 35-70, 1997. 
[6] J. Reardon-Anderson, The Study of Change: Chemistry in China, 1840-1949, Cambridge: Cambridge University Press, 1991, pp. 29-52.

[7] Y. Wang, "On mirror of chemical science: A source-book and first steps in chemistry (in Chinese)," China Historical Materials of Science and Technology, vol. 11, pp. 84-88, 1990.

[8] H. Chang, "The unification of the Chinese chemical nomenclature: 1912-1945 (in Chinese)," China Historical Materials of Science and Technology, vol. 24, pp. 123-132, 2003.

[9] W. Adolph, "Synthesizing a chemical terminology in China," Journal of Chemical Education, vol. 4, pp. 1233-1240, 1927.

[10] L. Ma and H. A. Webb, "Chemical terms in the Chinese language," Journal of Chemical Education, vol. 10, pp. 733-737, 1933.

[11] J. Fryer, "Scientific terminology: Present discrepancies and means of securing uniformity," in Proc. the General Conference of the Protestant Missionaries of China, Shanghai, May 7-20, 1890, pp. 531-551.

[12] C. W. Mateer, Chemical Terms and Nomenclature, Shanghai: American Presbyterian Mission Press, 1901, pp. i-xi.

[13] H. Chang, "The origin of the inert elements' Chinese names (in Chinese)," China Terminology, vol. 11, pp. 57-61, 2009.

[14] H. Chang, "The character Hua (change) in Chinese inorganic nomenclature: 1896-1945 (in Chinese)," Studies in the History of Natural Science, vol. 25, pp. 205-214, 2006.

[15] C. W. Mateer, Technical Terms: English and Chinese, Shanghai: Presbyterian Mission Press, 1904, pp. 1-8.

[16] H. Chang, "Yu Heqin's organic terms: A new beginning of Chinese systematic nomenclature of organic chemistry (in Chinese)," The Chinese Journal for the History of Science and Technology, vol. 26, pp. 222-230, 2005.

[17] J. Fryer and S. Xu, Vocabulary of Names of Chemical Substances, Shanghai: Jiangnan Arsenal, 1885, pp. 1-2.
[18] The National Institute for Compilation and Translation, Principles of Chemical Nomenclature (in Chinese), Nanjing: The National Institute for Compilation and Translation, 1933, pp. 31-43.

[19] H. Chang, "An historical perspective on the study of Chinese nomenclatures for benzene and aromatic, compounds: 1875-1945 (in Chinese)," Studies in the History of Natural Science, vol. 28, pp. 326-340, 2009.

[20] B. P. Block, W. H. Powell, and W. C. Ferneliu, Inorganic Chemical Nomenclature: Principles and Practice, Washington, DC: American Chem. Soc., 1990, pp. 30-45.

[21] R. B. Fox and W. H. Powell, Nomenclature of Organic Compounds, Cambridge: Oxford University Press, 2001, pp. 1-18.

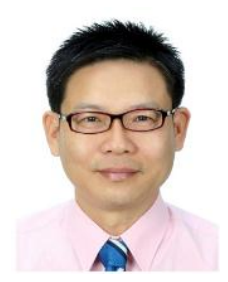

Hao Chang is a graduate of the School of Chemistry in Taiwan, with a master degree in physics. His doctorate degree, which was under the supervision of Prof. Hans-Werner Schuett, was conferred by the Institute of History of Science, at the Technical University of Berlin. He is currently a faculty member of the Center for General Education at I-Shou University, Taiwan. His research interests focus on the history of modern chemistry in China.

Dr. Chang was the chairman of the International Union of the History and Philosophy of Science, Division of the History of Science, National Committee of the Republic of China, from 2008 to 2014; a member of the editorial board of the Chinese Journal for the History of Science and Technology, from 2009-2013; and a council member of the Chinese Society for the History of Science and Technology, from 2009 to 2012. He is also on the editorial board of the Bulletin of History of Science, from 2014-2017. 